\title{
Software de apoyo a los docentes para mejorar el rendimiento profesional
}

\author{
Carlos U. Häubi Segura
}

Como maestros pasamos una gran parte del tiempo tratando de

organizar nuestros múltiples quehaceres: preparar clases; leer libros y artículos; llevar control de tareas, trabajos, y exámenes de los alumnos; desarrollar proyectos; controlar gastos, etcétera. Desgraciadamente, todavía no ha sido inventado el programa perfecto que haga todo esto, pero hay algunos "programitas" que pueden ayudar a mejorar nuestro rendimiento profesional y que vale la pena evaluar. Algunos tienen versiones gratuitas muy buenas. Espero que les sirvan los siguientes sitios:

Tipo de programa Qué puedes hacer con (ejemplos) estos programas

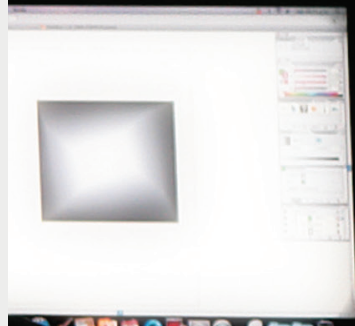

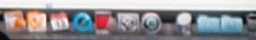

Herramientas

en línea para los

maestros de grandes $y$ chicos

Software

bibliográfico de datos y organiza tu información

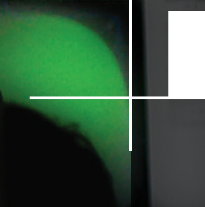

Mapas mentales y conceptuales

Axon Idea Processor

Personal Information

Management o PIM

\begin{tabular}{|c|}
\hline Software \\
de modelaje \\
y simulación
\end{tabular}

simulación

Software de estadística gratuito

Software de diseño y producción

Software para jugar con la ciencia
Genera líneas del tiempo, juegos, animaciones, clases grabadas, presentaciones

Haz búsquedas en bases

Estructura tus ideas en mapas mentales y expórtalos como archivos de Word, Powerpoint, Excel

Haz todo: hoja de cálculo, procesador de palabras, presentaciones, diseño, simulador, etcétera.

Organiza tus contactos, citas, textos, datos, escribe libros, guarda fotos, etcétera.

Haz que tus alumnos creen modelos y simulaciones

Analiza tus datos en forma gráfica y estadística

Pon tus ideas en papel electrónico y velas crecer

\section{Pinta moléculas}

Diseña un ala de avión Diviértete con la física Ve animaciones biológicas
Sitios de Internet sugeridos (URL)

http://free.ed.gov/index.cfm

http://www.teach-nology.com/

http://www.freetech4teachers.com/

http://www.sitesforteachers.com/

http://www.teach12.com

http://www.biblioscape.com/

http://www.refman.com/

http://www.endnote.com/

http://www.mindmapper.com

http://www.mindjet.com

http://www.inspiration.com

http://freemind.sourceforge.net

http://cmap.ihmc.us/conceptmap.html

http://web.singnet.com.sg/ axon2000/

$\sim=$ Alt +126

http://www.mytreedb.com/

http://www.treepad.com/

http://www.zootsoftware.com/

http://www.webideatree.com/

http://www.iseesystem.com

http://www.vensim.com/

http://www.powersim.com/

http://www.freestatistics.info/stat.php

http://www.r-project.org/

http://www.gnu.org/software/pspp/

http://www.statsoft.com/

http://sketchup.google.com/

http://www.flexsim.com

http://www.smartdraw.com

http://chemsketch.softonic.com/

http://www.grc.nasa.gov/WWW/K-12/airplane/foil2.html

http://phun.en.softonic.com/

http://www.johnkyrk.com/ 